\title{
ENSINO DA BIOLOGIA NAS SÉRIES INICIAIS DO ENSINO FUNDAMENTAL
}

\author{
Maria Madalena de Souza ${ }^{1}$
}

RESUMO: A epidemia de SARS-COV-2 lançou um novo panorama educacional e, apesar de muitas questões, como finanças e infraestrutura, a crise emocional decorrente do isolamento social tornou-se um desafio para professores e alunos. Como grande parte das pesquisas publicadas até agora tem como foco apenas o aluno, destacar a visão dos professores da rede pública é importante para que a comunidade veja seu valor e conhecimento no ensino a distância. O objetivo do estudo e demonstrar, por meio de palestras de professores, como a segregação afetou / contribuiu para o ensino de biologia, entender qual período da epidemia está confirmando a nomeação de classes, interação professor-aluno e aprendizagem significativa, em última análise, a atitude dos professores em relação à educação continuada, aspectos emocionais e eficiência. Como resultado, eles foram entrevistados professores de Biologia do Programa de Ensino Médio. Os resultados mostraram que o ambiente visual tornou-se um possível ambiente de aprendizagem para o processo de treinamento, havendo dificuldade em distinguir entre as atividades domiciliares e laborais. A experiência foi à necessidade de desenvolver as habilidades e conhecimentos da tecnologia educacional, nem sempre utilizada durante a formação inicial. O momento certo para reflexão sobre o sistema de ensino e como superar as falhas existentes.

Palavras-Chave: Educação. Isolação social (pandemia). Biologia. Professores.

\section{INTRODUÇÃO}

Um vírus de proporções letais e silenciosas foi capaz de mudar a rotina de pessoas em todo o mundo e proliferar rapidamente nos organismos de muitas, levando à morte. No fim de março, as perspectivas para o ano de 2020 foram adiadas, não existia liberdade, apenas o medo, a angústia, a incerteza e a insegurança se espalhavam por todos os contextos sociais.

A Organização Mundial da Saúde (OMS) em conjunto com profissionais da área tentam encontrar uma forma de reduzir a disseminação do vírus, conhecido

\footnotetext{
' Formada em Licenciatura em Pedagogia pela faculdade UNIUBE Universidade de Uberaba, Pós-graduada em Alfabetização e Letramento nas séries Iniciais e na EJA pelo instituto Superior de Educação e Cultura Ulysses Boyd. Cursando segunda graduação em Biologia pela Faculdade Faveni.
} 

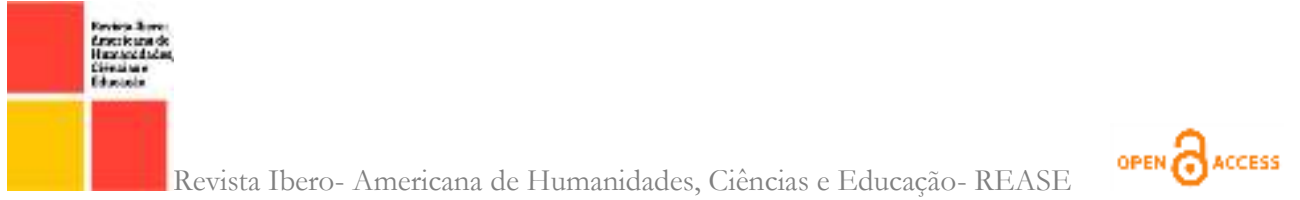

como SARS-COV-2. No entanto, pouco se sabe sobre ele, entretanto, a espera por um tratamento eficaz para controlar a pandemia é esperada por todos.

Nesse contexto, a principal forma de prevenção seria a contenção da propagação do vírus, com medidas básicas de higiene: lavagem das mãos e aplicação de álcool gel usa de máscaras e isolação social. Com o fechamento da maioria dos estabelecimentos comerciais, escolas e universidades, um novo cenário de relações sociais começa a se delinear tendo o isolamento como princípio fundamental.

Inúmeras categorias sofrem com o processo de flexibilização, principalmente a educação, mesmo que se trate de muitas questões como, por exemplo, finanças e infraestrutura, o problema $\mathrm{O}$ estresse emocional resultante do isolamento social tornou-se um desafio para professores e alunos.

Os professores da escola primária precisavam demonstrar eficiência e usar engenhosidade na organização de suas salas de aula. $\mathrm{O}$ ambiente visual tornou-se um possível ambiente de aprendizagem para o processo inventar.

Outro desafio que enfrentou foi a necessidade de desenvolver as competências e conhecimentos da tecnologia educacional, nem sempre na prática durante a formação inicial, que é a única forma de comunicação e relações professor-aluno.

$\mathrm{Na}$ era moderna, foi possível perceber mais fragilidades e desafios do sistema educacional historicamente discutido. As aulas de leitura pública foram suspensas e as longas aulas foram suspensas seguido, pois, nos termos do artigo 205 da Constituição da República:

A educação deve se concentrar no desenvolvimento pleno da personalidade humana e no fortalecimento do respeito pelos direitos humanos e pelas liberdades fundamentais. (Brasil, 1988).

Por causa do isolamento, os professores tiveram que se reabilitar para que pudessem continuar com as aulas e não deixar os alunos desamparados. O conjunto de discussão sobre as características biológicas da epidemia destaca a importância de os alunos compartilharem conhecimentos de ciências biológicas, permitindo que os alunos façam intervenções críticas e controversas. $O$ papel dos professores de Biologia foi importante na disseminação de informações para a comunidade escolar. proporciona a melhoria da qualidade de vida do ser humano, pois produz, 
em sua medida, a vasta quantidade de conteúdos científicos que abordam temas sensíveis. necessidade. Temas relacionados a questões ambientais; biotecnológico; a disseminação de doenças infecciosas e contagiosas e a formação do corpo humano e da saúde são alguns indícios da grande necessidade de compreensão desta ciência. (GOMES, 2018, página 20).

Nesse contexto, os professores encontraram grandes dificuldades, "Cerca de 88\% dos professores nunca deu um curso virtual antes. "(BENEDITO; FILHO, 2020, p.65). Preparação inadequada de dados dos novos meios de informação digital e tecnologia de comunicação, tornou-se mais obviamente, especialmente daqueles professores que estão acostumados com esses métodos tradicionais de ensino. Numerosos problemas e contrastes descritos na literatura educacional e observados na educação.

O processo de educação formal da formação inicial de professores no Brasil, onde os professores estão graduado na escola normal, nenhuma qualificação acadêmica é exigida, "Uma vez que é obrigatório, o ensino superior foi incorporado à legislação nacional apenas na segunda metade da década de 1990. " (SEGATTO; LOUZANO, 2019, p.184) Isso favorece a falta de Ocupação.

Ao contrário de outros países desenvolvidos, no Brasil ainda havia falta de atenção ao currículo e formação de professores, e distância da escola, ensino superior eles se concentram apenas no conceito. Porém, uma graduação sem a prática de ensinar e interagir com os alunos não seria adequado para a docência. Louzano et al (2019, p. 153), afirma que "o caminho

Um aluno é testado para ver se ele ou ela tem a capacidade de ser um professor competente com base na ideia de que deve demonstrar sua capacidade de ser um professor, não apenas essa teoria." Com o surgimento de programas de formação de professores como o Programa Institucional de Bolsas de Iniciação à Docência (PIBID) e o Programa de Residência Pedagógica (PRP), além de os estágios supervisionados, que exigem amplo conhecimento dos alunos de graduação, contribuem para a formação efetiva dos alunos.

No entanto, esses programas não atendem às necessidades dos alunos e, neste caso, o currículo matriculado para jovens alunos, busca, por meios práticos, os verdadeiros truques do ofício. 
2. OBJETIVOS

\subsection{Objetivos gerais}

Nessa visão, o objetivo deste estudo foi analisar as palestras de professores de biologia, de uma rede social, de uma escola de ensino médio, de municípios da região brasileira, para mostrar como o isolamento / impacto social no ensino de biologia, no intuito de compreender como o período epidêmico garantiu a constituição das classes, em Interação professor-aluno com aprendizagem significativa e, por fim, analisar a atitude do professor em relação à formação continuada, aspectos emocionais e eficiência.

\subsection{Objetivos específicos}

- Analisar o estudo e demonstrar, por meio de palestras de professores, como a segregação afetou / contribuiu para o ensino de biologia.

- Analisar o momento certo para reflexão sobre o sistema de ensino e como superar as falhas existentes durante esse processo.

\section{DESENVOLVIMENTO}

Apesar dos avanços apresentados, a maioria das universidades públicas carece de infraestrutura e expertise de profissionais para contribuir com a formação inicial.

Estudo recente sobre cursos de formação de professores no país indica a persistência dessa desconexão entre o ensino em uma universidade (pública ou privada) e o que o professor precisa fazer em sala de aula. (NASCIDO, 2019, p. 25).

Entre os desafios óbvios da sala de aula invisível, também está o trabalho em casa. A maioria dos educadores são pais e não têm espaço suficiente para dividir suas carreiras. Crianças em idade escolar, e aberrações podem ocorrer devido à interferência de pessoas que vivem na mesma área.

Além disso, quando podem se preparar para as aulas, muitos alunos que não têm acesso à Internet ou os pais optam por deixar seus filhos fazerem trabalhos domésticos durante as aulas. "[...] Sabe-se que 20\% dos lares brasileiros não têm 

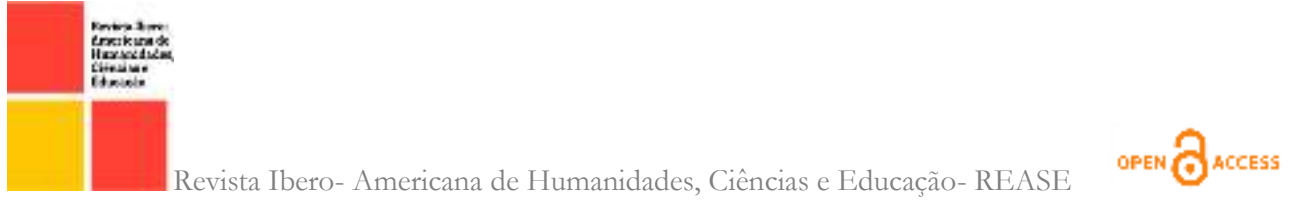

acesso à Internet, onde moram 7 milhões de alunos, 95\% dos quais estão matriculados em escolas publicamente. "(COLEMARX, 2020, página 16).

Nesse novo ambiente, é possível perceber limitações, mesmo reais, para professores / pais / alunos que desejam aprimorar o aprendizado dos jovens. Contudo, professores que não são pagos apenas pela escola para renovar empregos, mas também pelos pais para ajudá-los a ensinar seus filhos.

A jornada de trabalho é muito alta, pois o professor ainda pode ser contatado pelos pais ou alunos em qualquer sistema. Outro fator a ser considerado são os métodos eficazes de ensino de Biologia, pois são importantes para promover a participação dos alunos, porém, por meio de categorias práticas para professores procuram reduzir a ausência desta prática com slides mais dinâmicos, discursos curtos também perguntas.

No entanto, isso nem sempre acontece, pois, a maioria das atividades remotas é para exercícios em livros ou perguntas. Um dos melhores pontos de atividades remotas é aprendizagem de professores e paixão por novas tecnologias, que mais tarde contribuirão para a sala de aula.

Esta nova abordagem para educar os jovens trará coisas novas para a educação. Tornar os modelos de aprendizagem tão óbvios que, antes da epidemia, era impossível, seria possível aceitação no tempo presente. Por exemplo, educação em casa ou educação em casa pode ser definida como:

A substituição total da escolaridade é a educação domiciliar, onde a
responsabilidade pela educação formal das crianças é repassada aos próprios
pais ou responsáveis. Uma criança ou adolescente não entra em uma
instituição educacional, seja em público ou em privado. As aulas são
ministradas em casa pelos pais ou por professores particulares contratados
por eles. (ISILVA, 2020).

População brasileira depende de instituição pública. No entanto, com as aulas online os pais mesmo com dificuldades se organizaram e conseguiram contratar um reforço ou um educador mais próximo.

Essa vivência reflete os tempos passados, em que não existiam escolas públicas, e a família era a principal responsável por educar os jovens. Nos Estados Unidos, a educação domiciliar já é uma prática comum, por ser regularizada. No 
Brasil, segundo os dados da Associação Nacional da Educação Domiciliar (ANED), "cerca de 5000 estudantes entre 4 e 17 anos aderiram à modalidade".

Contudo, está no processo de aceitação e regulamentação, segundo o Ministério da Educação, lei n.o $2401 / 19$ caso seja aprovada pelo poder Executivo competem aos responsáveis:

Muitos discutem sobre essa forma de adquirir conhecimento, pois a grande parte da [...] Atualize-se anualmente, através da plataforma da Secretaria de Educação, com a introdução de um programa de educação pessoal que coincide com o novo ano letivo. $O$ aluno matriculado em educação domiciliar será encaminhado, para fins de obtenção de certificado de estudos, aos exames anuais administrados pelo Departamento de Assuntos Internos. Educação. (BRASIL, 2019).

Segundo essa visão, as mudanças serão muitas e isso exigirá profissionais capacitados para acompanhar a evolução da educação. Além disso, o investimento em treinamento continua a ser importante no mercado de trabalho, especialmente no que diz respeito à utilização das Tecnologias Digitais de Informação e Comunicação (TDICs). Esta forma de comunicação é amplamente utilizada pelos jovens, que nos últimos anos têm se tornado cada vez mais conectados às redes sociais e aos serviços digitais.

Porém, a tecnologia digital não tem sido reconhecida pelas instituições de ensino, pois muitos professores possuem visões restritivas, desconhecimento, interesse e dificuldade com plataformas digitais. À medida que a epidemia avança, aumenta a importância do uso de TDICs, onde é possível continuar as aulas em diferentes níveis de ensino Quanto ao ensino de Biologia, segundo Gomes (2018, pág. 20):

Em meio à complexidade do processo de ensino e aprendizagem de Biologia no Ensino Médio, o uso do conhecimento digital e das tecnologias de comunicação surge como uma forma de simplificar o processo, na abordagem de diversos temas pelo professor, mas é necessário compreender os aspectos do ensino integrado para ser utilizado de forma eficaz na era digital plena.

Portanto, a consideração da formação de professores deve ser considerada no contexto atual. Dado que os professores têm a responsabilidade de criar métodos de 
treinamento individualmente. No entanto, está ao nível do profissionalismo e mais ainda para tentar manter-se atualizado.

O conhecimento dos professores, principalmente daqueles que lecionam Biologia, também deve ser relevante e assim por diante, à medida que os detalhes variam e melhoram a cada momento. De acordo com essas observações:

[...] A formação continuada de professores não deve ser interpretada como um processo de coleta de saberes, e saberes, mas deve buscar o desenvolvimento do profissionalismo e da personalidade, com foco no processo de desenvolvimento de competências políticas, técnicas e humanas. Com o objetivo de desenvolver profissionalismo. (FERREIRA; NETA, 20I2, p. 965).

O ensino à distância deixa claro que os professores de todos os níveis de ensino nas escolas públicas devem se comprometer com o aumento da alfabetização digital por meio de educação continuada. Portanto, ao isolar-se da sociedade e às mudanças na concepção de educação, os professores são amplamente reconhecidos pelos pais e pela comunidade escolar como agentes.

É importante para a formação do aluno. Diante do exposto, é importante focar na substituição dos professores do ensino fundamental da rede pública quando se deparam com problemas de EAD, uma vez que grande parte das pesquisas publicadas até o momento tem como foco os alunos.

\section{LICENÇA DE BIOLOGIA: EDUCAÇÃO DE SAÚDE EM CIÊNCIAS DO ENSINO}

A Educação em Saúde (ES) está dividida em cursos específicos e foi concebida como campo de estudo e prática em Ensino de Ciências (CE) (VENTURI; MOHR, 2019). No desenvolvimento escolar, as atividades de ensino superior devem ser reduzidas ao mínimo e estar de acordo com as metas e objetivos do sistema escolar.

Reconhecida como um conjunto de atividades dentro da escola, também desenvolvida de forma sistemática para fins de ensino, ou seja, para fins relacionados ao ensino e aprendizagem, por meio da construção do conhecimento, do pensamento independente e pensar sobre determinado assunto, tema ou conteúdo, relacionado à 
vida individual e coletiva (MOHR, 2002) e compreender a importância da responsabilidade socioambiental (VENTURI, 2018).

Além disso, e em consonância com os objetivos modernos da EC, a ênfase no ensino superior "deve ser o de aumentar a capacidade de analisar, criticar e identificar as relações múltiplas por tipo de objetos e problemas estudados pela sociedade".

(VENTURI; MOHR, 2015, p.o2), para proporcionar autossuficiência diante dos problemas, debates e tomadas de decisão necessárias no cotidiano do mundo moderno. Essa compreensão do ensino superior abraça a ideia de ensino no contexto da escola, está alinhado com os objetivos e estratégias de ensino e aprendizagem científica.

A partir do desenvolvimento de conhecimentos científicos que possibilitem uma compreensão abrangente e abrangente do mundo, a educação superior pode contribuir para o processo de Alfabetização Científica e Tecnológica (ACT) (VENTURI, 2018). Fourez et. al (1997) considera a LEI um processo que as pessoas podem aplicar conhecimento das instituições disciplinares, para defini-las de forma diferenciada, a fim de cumprir seu papel de autonomia na sociedade tecnológica (FOUREZ et al., 1997).

Sendo "o processo pelo qual você adquire a linguagem das Ciências Naturais definições, que formam a base para uma pessoa expandir sua base de conhecimento, cultura, como uma cidadania inclusiva"(LORENZETTI; DELIZOICOV, 20oI, p. 52).

No entanto, o atual ensino superior oferecido na escola não possui método de ensino (MOHR, 2002). Essa obra no Brasil tem seus pilares nas estradas especialistas, limpadores e sanitaristas que estão comprometidos com mudanças comportamentais rápidas (SILVA et al., 2010), vêem o comportamento humano como um resultado direto de informações obtidas de outras pessoas.

Portanto, o ensino superior é mais estratégico informações e a transmissão de informações sobre o corpo humano, normas e recomendações, a serem estudadas para prevenção de doenças (SILVA; TEIXEIRA, 2015). Como regra, a ideia geral de um ensino superior é aceita, é totalmente diferente da perspectiva do ensino (baseada no 
debate e na construção do conhecimento) e está totalmente ligada à educação bancária e ao modelo médico (MOHR, 2002).

A prática geral de promoção do ensino superior na escola muitas vezes é ineficaz, desvinculada da autenticidade do aluno, não conduz comportamentos considerados saudáveis e não favorece a construção de conhecimentos científicos.

(MOHR, 2002). Além disso, na ausência do processo de ACT, os cidadãos ficam expostos à disseminação de informações falsas, científicas e supersticiosas, que podem dificultar a compreensão do mundo e a tomada de decisões sensatas e adequadas, nas mais diversas situações, envolvendo sua saúde e bem-estar, como visto no cenário., que vivemos hoje.

Repensar estratégias e métodos de ensino, aprimorar materiais didáticos e aprimorar o raciocínio e a discussão são ações fundamentais propostas pelo Projeto de Licenciatura em Biologia, para superar o bom senso de Profissionais éticos no ensino superior realizado na escola.

Desta forma, o objetivo geral do trabalho foi: "formular propostas teológicas e doutrinárias de várias abordagens da educação para a saúde na educação escolar em ciências" (UFPR, 2020, p.or). Até o momento, os seguintes objetivos específicos foram estabelecidos:

\footnotetext{
Pesquisar, discutir e discutir as teorias, tecnologias e disciplinas das Ciências da Saúde no Ensino das Ciências. - Criar e produzir materiais didáticos, videoaulas, materiais de distribuição Educação em Ciências, Saúde, Ensino de Ciências no Ensino Fundamental; - Avaliar, analisar e discutir, desde o planejamento e relatórios, até o desenvolvimento de informações de educação profissional em desenvolvimento do projeto (UFPR, 2020, p.oI).
}

\section{CONCLUSÕES}

Dado o contexto educacional por trás da epidemia, conheça a experiência de Biólogos da rede social, vão contribuir para a discussão do tema em discussão, mostra a dificuldade e a vitória que o professor consegue, por causa do longo ensino.

Quando entendemos que ensinar transmite conhecimento, fomos levados a aprender mais sobre como criar oportunidades para sua produção. A relação ensinoaprendizagem é uma conversa, desenvolvida entre as muitas adaptações, a educação 
geral foi substituída por novas plataformas digitais. À procura de competências e aptidões que até então, sem qualificações.

Além disso, o método de avaliação do aluno tornou-se mais complexo, indicando que a prática de avaliação alternativa, como a avaliação, está desatualizada. (OLIVEIRA, 2020, pág. 37).

No atual contexto do COVID-ı9, onde ocorre a fusão entre o virtual e o presencial, não se pode mais aplicar a educação geral e, por consequência, os padrões de teste padrão, apenas resta corrigir a submissão individual e social à continuação da ação. (PASCHOALINO; RAMALHO; QUEIROZ, 2020, página 127).

Isso é evidenciado pelas falas que a formação necessária de professores de Tecnologias Digitais de Informação e Comunicação, a fim de desenvolver competências.

Os requisitos para o processo de ensino e aprendizagem, existem no conceito de educação inicial e continuada, a fim de atender às necessidades atuais decorrentes das divisões sociais e nova ordem de linguagem e trabalho de comunicação. A este respeito, segundo Silva, (2018, pág. 34-35):

Reconhecendo a importância do assunto, conscientizando a comunidade sobre a importância da inteligência na época do vírus (SARS-COV-2), na formação do aluno frente aos jovens perspectiva educacional.

Analisar os discursos dos professores de Biologia do segundo escalão, em termos de arte, eficiência, definições e questões emocionais, contribuirá para divulgar a importância dessa categoria de pessoal durante a epidemia, enfatizando que o professor precisa ser consistente.

É muito reconhecível porque, embora não seja preparado profissionalmente e psicologicamente, é ele está sempre procurando revitalizar e ensinar os alunos.

Embora os alunos tenham demonstrado dificuldade em praticar o ensino a distância, os professores tiram sua privacidade, mesmo com mudanças inesperadas no estilo de ensino sem tempo para se preparar emocional e profissionalmente, mostraram-se eficientes e prudentes e, acima de tudo, comprometidos com os alunos.

Portanto, relate a experiência desses profissionais ajudará a valorizar o trabalho realizado pelos professores dos alunos e da comunidade escolar, e servirá de 

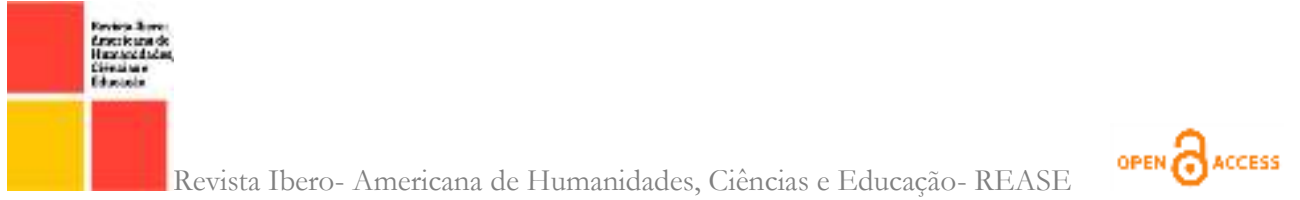

exemplo ou apoio aos alunos de graduação que não os possuíam experiência no ensino desta epidemia. E ainda, como o trabalho está sendo feito nos municípios da região do Brasil, os resultados ajudarão a informar o estado atual da educação brasileira, pouco enfatizado no país.

Ao isolar-se, ficou muito claro que o professor é importante no ensino e na formação dos alunos, e a comunicação entre eles é fundamental no processo de ensino e aprendizagem.

O treinamento inicial de professores deixa lacunas no uso da tecnologia, portanto, o treinamento adicional deve estar na mente dos profissionais acadêmicos. Licenciado em A biologia, no segundo nível, requer uma atualização das informações de conteúdo, mas use discrição no processo de troca lógica dessas informações, a fim de pode despertar o interesse dos alunos.

Outro ponto importante desse processo é o reconhecimento da complexidade da estrutura como acesso à internet de qualidade e / ou equipamentos disponíveis, por exemplo, para fazer estratégias de planejamento de professores, a ferramenta mais importante para visitar diversidade e poder social dos alunos.

Em termos de eficiência, as palestras mostram uma combinação de lição de casa e lição de casa, há uma quebra de privacidade, os professores compartilham suas postagens habitação, que sempre se limita ao desenvolvimento da sala de aula.

Os professores apontam que sua comunicação com a comunidade é excessivamente solicitada e, em qualquer caso, horas, estendendo a jornada de trabalho do professor. No entanto, o acúmulo de empregos, o uso de tecnologia e a falta de contato cara a cara com os alunos, têm perturbado psicologicamente muitos casos, que às vezes destacam depressão, ansiedade, frustração, fraqueza e ansiedade exagerada.

Diante do exposto, grandes mudanças levam à evolução e maior aprendizado, apesar dos problemas que advêm do ensino de longo prazo, os professores se destacarão significativamente em reforço emocional com ênfase e obtenção de resultados positivos por meio dos TDICs propostos pela escola. 
E todas essas experiências contribuirão para o desenvolvimento de sequências didáticas, seja em sala de aula, abordagens mistas ou visuais, e para a continuidade da reconstrução do sistema educacional brasileiro.

\section{REFERÊNCIAS}

AIRES, S.F.; MADEIRA, C.A.G. Desenvolvimento de jogos educacionais Digital: relato de experiência no framework PlayEduc. Nova Revista Tecnologia da educação. v. I8, não. I, 2020.

AGUIAR, Felipe. A epidemia de covid-19 e as demandas de atividades educativas. Revista Diálogos Acadêmicos, Fortaleza, v. 9, n. I, página 59, 2020. Disponível com <ihttp: //revista.fametro.com.br/index.php/RDA/article/view/268> Acesso em:

ANED. Detalhes sobre a educação domiciliar no Brasil. Associação Nacional de Educação Domiciliar, 2010. Disponível em: https://www.aned.org.br/sobrenos/quem-somos-aned. Acesso em:

BARBOSA, André.; VIEGAS, Marco.; BAPTISM, Regina. Sala de aula para horários epidemia: relatos de experiência de professores de ensino superior com turmas remotas. Rev. Augusto, v. 25, n. 51. página. 277, Rio de Janeiro, 2020. Disponível em:

https://apl.unisuam.edu.br/index.php/revistaaugustus/article/view/565> Acesso em:

BENEDICT, Samiles. Ç.; FILHO, Peter. Educação básica no Ceará durante a epidemia coronavírus (covid-19): ideias e desafios no estado da educação brasileiro. Nova Revista Paideia - Revista Interdisciplinar de Educação e Pesquisa. Brasília / DF, v. 2, n. 3.p. 58-71-2020. Disponível em: 〈http://novapaideia.org/ojs/ojs-2.4.8 3 / index.php / RIEP / article / view / 58> Acesso em:

BORN, Bárbara. Transformando a formação de professores fazendo: desafio potencial: papel a fazer na formação de professores primários. Instituto Península, Profissão Docente. - Io editor. - Claro Paul: Moderno, p. 25, 2019.

BRASIL. lei no 240I/19, de 13 de julho de 1990. O projeto cria leis de educação domiciliar no Brasil. Câmara dos Deputados, Brasília - DF, 2020. Disponível em 
<amara.leg.br/noticias/556888-projetocria-regras-para-educacao-domiciliar-nobrasil/> Acesso em:

BRASIL. Constituição de 1988. Constituição da República Federativa do Brasil: promulgada em 5 Outubro de i988. Disponível em: www.mec.gov.br/legis/default.shtm. Acesso em:

COLEMAX. Na proteção da educação pública voltada para a igualdade social: por quê a equipe não deve aceitar aulas remotas. Rio de Janeiro, 2020. Disponível em: http://www.colemarx.com.br/wp-content/uploads/2020/o4/Colemarx-textocr\% $\mathrm{C}_{3} \% \mathrm{ADticoEaD}-2 . p d f$. Acesso em:

CHATES, TJ ideias educacionais em tempos pós-realidade. (Series Collected Studies, Volume 14). Jundiaí: Paco Planning, 2017.

ENPEC. ACTIO, Curitiba, v. 2, n. 3, página. 133-150, outubro / dezembro. 2017. Disponível em: https://periodicos.utfpr.edu.br/actio/article/view/6818/4676. Acesso em:

FOUREZ, G; ENGLEBERT-LECOMPTE, V.; FUNCIONÁRIOS, D.; MATHY,

PARA.; TILMAN, F. Literacia científica e técnica. Argentina: Edições Colihue, 1997. GI (2021). Brasil chega a 373.000 com a morte de Covid: 1.553 países registrados Morte em 24 horas Disponível em: https://gi.globo.com/bemestar/coronavirus/noticia/2021/04/ı8/brasil-chega-a-373milmortos-por-covid-pais-registrou-I553-mortes-em-24-horas. ghtml. Acesso em: 